\title{
A LÍQUIDA PALATAL DO PORTUGUÊS NA DIACRONIA E NA AQUISIÇÃO DA ESCRITA
}

\author{
THE PALATAL LIQUID OF PORTUGUESE IN DIACHRONY \\ AND ACQUISITION OF WRITING
}

\author{
Franciele Collovini TAVARES 1 \\ Ana Ruth Moresco MIRANDA²
}

Resumo: A líquida palatal do português foi introduzida no sistema consonantal a partir de processos ocorridos durante a evolução do latim ao português, os quais, de acordo com Silva (2001), são decorrentes do fenômeno da palatalização. Para Matzenauer-Hernadorena (1994), do ponto de vista melódico, isto é, em termos segmentais, a líquida palatal tem uma estrutura complexa, pois apresenta duas articulações, uma primária, no ponto de consoante, e outra secundária, no nó vocálico. Considerando-se a complexidade da consoante, este estudo tem o objetivo de investigar o comportamento da líquida palatal, observandose a diacronia e a aquisição da escrita. Para a composição do corpus da pesquisa foram analisados dados de escrita de crianças brasileiras e portuguesas pertencentes aos estratos 3 e 4 do BATALE - Banco de Textos de Aquisição da Linguagem Escrita. A amostra utilizada para análise dos processos envolvidos na diacronia das soantes palatais foi composta por dados extraídos de livros que tratam da evolução do latim ao português. Os resultados demonstraram que os processos verificados na diacronia e na aquisição da escrita ocorrem em direções opostas. Os resultados apontaram que há uma simplificação das consoantes complexas pelas crianças na aquisição da escrita enquanto ocorre o processo inverso na diacronia da líquida palatal.

Palavras- chave: Líquida palatal. Aquisição da escrita. Diacronia.

\begin{abstract}
The palatal liquid of Portuguese was introduced into the system from processes that occurred during the evolution from Latin to Portuguese which, according to Silva (2001), are due to the palatalization phenomenon. For MatzenauerHernadorena (1994), from the melodic point of view, that is, in segmental terms, the palatal liquid has a complex structure because it has two articulations, one primary at the consonant point and another secondary at the vocalic node. Considering the complexity of this consonant, this study aims to investigate the behavior of palatal liquid, considering diachrony and writing acquisition. For the composition of the research corpus, were analyzed data of Brazilian and Portuguese children belonging to strata 3 and 4 of BATALE - Banco de Textos de Aquisição da Linguagem Escrita. The sample used to analyze the processes involved in palatal sound diachrony was composed by data extracted from books that deal with the evolution from Latin to Portuguese. The results showed that the processes verified in diachrony and in the acquisition occur in opposite directions. The results showed that there is a simplification of complex consonants by children in the acquisition of writing while the reverse process occurs in palatal sound diachrony.
\end{abstract}

Keywords: Palatal liquid. Acquisition of writing. Diachrony.

\footnotetext{
1 Tavares. UFPel. E-mail: francollovini@hotmail.com. ORCID: https://orcid.org/0000-0001-6900-2213 
- | A líquida palatal do português na diacronia e na aquisição da escrita

\section{Introdução}

Este artigo tem como objetivo descrever e analisar os erros de grafia da líquida palatal produzidos por crianças brasileiras e portuguesas na busca de relações entre os processos envolvidos na diacronia e aqueles encontrados na aquisição da escrita da líquida palatal. Destaca-se a importância da relação entre a diacronia e a aquisição da linguagem reportada nos estudos linguísticos que apontam para o fato de que, em ambas as perspectivas, ocorrem processos que marcam a transformação da língua.

$\mathrm{Na}$ evolução do latim ao português, o sistema consonantal passou por alguns processos fonológicos, muitos deles similares aos que ocorrem na aquisição da linguagem oral e escrita. No sistema consonantal do latim clássico não havia consoantes palatais, $/ K, \mathrm{n}, \int, 3 /$, segmentos que surgiram a partir de processos ocorridos durante a evolução do latim ao português. Dentre eles, têm-se os que envolvem o surgimento da líquida palatal $/ K /$, consoante que suscita discussões sobre seu status fonológico e que, por seu comportamento peculiar, é considerada complexa por autores como MatzenauerHernandorena (1994) e Wetzels (1997).

Considerando que as consoantes palatais $/ K, \mathrm{n}, \int, 3 /$ não faziam parte do inventário fonológico do sistema consonantal do latim clássico, as palatalizações românicas, não só as portuguesas, resultam de complexas mudanças fonéticas. Para Silva (2001), a palatal líquida $/ \Lambda /$ deriva da palatalização de sequências como: /li, lli, $k l, g l, p l /$.

No processo de aquisição da linguagem, a criança desenvolve paulatinamente o conhecimento sobre as unidades e as regras de funcionamento da língua em todos os âmbitos da gramática, inclusive o fonológico. Os segmentos consonantais e vocálicos são adquiridos progressivamente para formar o sistema linguístico das crianças. Essa progressão se caracteriza pelo aumento da complexidade segmental e prosódica dos segmentos e das estruturas, das menos marcadas, adquiridas mais precocemente, às mais marcadas, cujo domínio é mais tardio. Assim, o conhecimento fonológico vai ganhando complexidade. Matzenauer-Hernandorena (2002) destaca que um aspecto comum à aquisição e à variação é o funcionamento fonológico da língua observado em ambos os processos.

Estudos que tratam da aquisição da linguagem têm mostrado que a líquida palatal é uma das consoantes adquiridas mais tardiamente pelas crianças, em torno dos 3:6 para Ribas e Mezzomo (2004) e por volta dos 4:0 para Matzenauer-Hernandorena (2000).

Tendo em vista o período de aquisição da consoante $/ K /$ e as estratégias produzidas pelas crianças ao adquiri-la, observa-se, ao comparar o processo de aquisição da líquida 
palatal com o processo de aquisição das demais consoantes que, quanto mais tardia é a sua aquisição, mais estratégias podem ser utilizadas pela criança na tentativa de produção da consoante.

Já o processo de aquisição da escrita envolve a compreensão dos princípios do sistema alfabético e, portanto, atenção aos elementos de segunda articulação da linguagem, os fonemas, os quais serão postos em correspondência com os respectivos grafemas que os representam no sistema de escrita da língua. É notório que a criança pensa sobre sua escrita e usa diferentes estratégias para grafia dos sons. Essas estratégias, de acordo com Miranda (2014) em investigações desenvolvidas pelo GEALE³, são capazes de revelar as hipóteses das crianças a respeito do sistema ortográfico que estão adquirindo, bem como acerca de seu conhecimento fonológico.

Considerando-se a complexidade da líquida palatal, tanto no processo de aquisição da fala quanto na evolução do latim ao português, este estudo se justifica pela relevância dos dados de escrita inicial, extraídos do BATALE, os quais são capazes de acrescentar argumentos às discussões referentes à fonologia, uma vez que tratam de dados de aquisição de linguagem.

\section{Considerações teóricas}

\section{Diacronia}

Tendo em vista que as línguas mudam e que durante o processo de evolução sofrem transformações comuns a toda língua falada, a evolução das línguas foi e continua sendo tema de interesse para os pesquisadores. O processo de transformação das línguas é sempre lento e, no caso do latim ao português, necessitou de vários séculos até a completa transformação, resultando no português moderno. Segundo Williams (2001), os registros mais antigos do português surgiram no final do século XII, marcando o início histórico do português arcaico. Conforme Câmara Jr. (1975), a língua escrita reflete as condições da língua comum e acompanha sua evolução. Com base nesse pressuposto, o autor divide a língua portuguesa em período arcaico, que vai até o séc. $\mathrm{XV}$, e período moderno.

3 GEALE - Grupo de Estudos sobre a Aquisição da Linguagem Escrita - surgiu em 2001, a partir do desenvolvimento do projeto de pesquisa intitulado Aquisição da Escrita: ortografia e acentuação, com o objetivo de desenvolver uma análise linguística para dados de escrita inicial. O grupo é coordenado pela professora Ana Ruth Moresco Miranda (CNPq - Processos n. 309645/2017-4 e 436882/2018-3).

4 BATALE - Banco de Textos de Aquisição da Linguagem Escrita - iniciado em 2001 e ainda em construção, é o banco de textos utilizado como base nos estudos do GEALE. Os textos que o compõem são de escrita espontânea obtidos a partir de oficinas de produção textual. Atualmente o banco é composto por 9 estratos, conforme link: https://wp.ufpel.edu.br/geale/ 
- | A líquida palatal do português na diacronia e na aquisição da escrita

A tradição literária do latim teve seus registros primários no século III a. c., antes disso, existiram somente inscrições sem valor literário, que expunham os traços da língua falada pelo povo. Já o latim vulgar era falado por pessoas incultas e analfabetas, dentre elas estavam os soldados, agricultores, escravos, artistas de circo e homens livres, com a finalidade de uma comunicação mais rápida entre as pessoas. O latim vulgar foi se expandindo em relação ao latim clássico, porém, não houve a sucessão de uma língua pela outra, ambas coexistiram. Com o passar do tempo, o latim clássico foi perdendo espaço para o latim vulgar cujo uso era mais recorrente entre as classes menos instruídas e, por isso, tido como um falar das classes populares.

Visto que este trabalho tem como um de seus objetivos analisar a evolução fonológica do latim, escolheu-se usar dados do latim vulgar para o estudo, considerando que era a língua falada pelo povo e também porque há distinções entre o sistema consonantal do latim clássico e o do latim vulgar.

De acordo com Williams (2001), a distinção do latim vulgar de uma região para outra resultou em diversas línguas românicas devido às seguintes causas:

i. relativo isolamento geográfico dos grupos entre si;

ii. desenvolvimento de unidades políticas separadas;

iii. variação cultural e circunstâncias educacionais;

iv. período de romanização;

v. diferenças dialetais na língua dos colonos itálicos;

vi. substratos linguísticos originais;

vii. superstratos linguísticos subsequentes.

De acordo com Nunes (1975) e Coutinho (1976), embora o português já existisse desde o século IX, conforme comprovam os poucos documentos que datam o período, somente a partir do século XII que se tem o registro de documentos oficiais escritos. Documentos que apresentam muitas marcas linguísticas do latim vulgar, comprovando que a mudança não é abrupta. O processo de transição de uma língua para outra ocorre de forma gradativa, em que certos segmentos se modificam: no caso do latim ao português, o que caracteriza o surgimento das consoantes palatais $/ K, \mathrm{n}, \int, 3 /$ é o processo de palatalização.

Ao tratar dos primeiros registros das soantes palatais, Williams (2001, p. 36-37) aponta que: 
Pedro A. d'Azevedo assevera (RL, IX, 263) que a primeira ocorrência datada de Ih é num documento de 1269 e a de $n h$ num documento de 1273. Entretanto, essas datas podem ser ligeiramente recuadas, pois o Livro de D. João Portel, que Pedro A. d'Azevedo publicou subsequentemente, consigna lh (lha) num documento de 1265 e $n h$ (em ganhar) num documento de 1267. A teoria geralmente aceita para a origem dessas grafias é a de que foram elas tomadas de empréstimo provençal .

Sobre o processo de evolução das soantes palatais, Williams (2001) aponta que nas primeiras escritas do português o $n i, n$ e $n n$ foram usados para grafar o $/ \mathrm{n} /$ e que $l i, l$, ll usados para grafar o $/ \kappa$. Para Nunes (1967), a líquida palatal originou-se dos seguintes processos:

- os grupos consonantais $c l, t l, g l, p l$, quando em posição intervocálica, são reduzidos a $l h$ : speclu> espelho, vetlu> velho, tegla $>$ telha e scopulum $>$ escolho.

- o gl, quando precedido de consoante, torna-se $l h$ : senglo $>$ selhos, cingla $>$ sinlha.

De acordo com estudos de Câmara Jr. (1975), Coutinho (1976), Nunes (1967, 1975), Silva (2001), Teyssier (2004) e Williams $(2001)^{5}$, foram verificados os seguintes processos envolvendo a evolução da líquida palatal, conforme Quadro 1.

Quadro 1. Tipos de processos envolvidos na evolução das líquidas palatais

\begin{tabular}{|l|l|}
\hline Processo & Exemplo \\
\hline $\mathrm{cl} \rightarrow \mathrm{lh}$ & oc(u)lu $>$ olho \\
\hline $\mathrm{pl} \rightarrow \mathrm{lh}$ & scop $(\mathrm{u}) \mathrm{lu}>\mathrm{scoclu}>$ escolho $^{6}$ \\
\hline $\mathrm{bl} \rightarrow \mathrm{lh}$ & trib(u)lu $>$ trilho \\
\hline $\mathrm{gl} \rightarrow \mathrm{lh}$ & teg(u)la $>$ telha \\
\hline $\mathrm{tl} \rightarrow \mathrm{lh}$ & vetlu $>$ velho \\
\hline $\mathrm{Il} \rightarrow \mathrm{lh}$ & caballariu $>$ cavalheiro \\
\hline $\mathrm{ll} \rightarrow \mathrm{lh}$ & alliu $>$ alho \\
\hline $\mathrm{li} \rightarrow \mathrm{lh}$ & filiu $>$ filho \\
\hline
\end{tabular}

Fonte: Elaboração própria

5 Foram analisados para este estudo autores que consultaram fontes diretas da língua e outros que fazem suas análises a partir de gramáticas históricas.

6 Este processo de formação da líquida palatal foi mencionado apenas por Coutinho (1976). 
- | A líquida palatal do português na diacronia e na aquisição da escrita

\section{Aquisição da escrita}

A fim de atingir o objetivo deste estudo, foram analisadas também as estratégias usadas pelas crianças no processo de aquisição da escrita da líquida palatal, consoante que tem aquisição mais tardia tanto na fala quanto na escrita. Para isso, faz-se importante compreender como ocorre esse processo e quais estratégias a criança utiliza durante a aquisição.

$\mathrm{Na}$ aquisição da linguagem, a criança adquire gradualmente o sistema linguístico e desenvolve um conhecimento internalizado sobre o funcionamento e as unidades da língua. Logo, segue uma ordem de aquisição, em que determinados segmentos são adquiridos antes de outros e, nesse processo, a criança, guiada pelas classes naturais, utiliza estratégias na tentativa de produção dos segmentos que ainda não fazem parte de seu inventário fonológico.

No desenvolvimento linguístico, apesar de toda complexidade inerente às gramáticas, a aquisição do sistema ocorre rapidamente, sem apresentar fenômenos estranhos ao funcionamento da língua. Nesse sentido, Miranda e Matzenauer (2010) destacam que, durante a aquisição da linguagem, quando a criança não realiza um segmento ou emprega outro em seu lugar, age de forma natural e espontânea, produzindo formas em consonância com fatos que fazem parte das gramáticas de diferentes línguas.

Considerando que há uma ordem de aquisição das consoantes, Matzenauer e Costa (2017) expõem, na Figura 1, a ordem de aquisição desses segmentos no português. A seguir, é possível observar a sequência e os agrupamentos de consoantes ao longo da aquisição do inventário fonológico. As soantes palatais têm aquisição mais tardia, sendo a nasal mais precoce e a líquida palatal uma das últimas a serem adquiridas.

Figura 1. Ordem de aquisição das consoantes do português

\section{$/ \mathbf{p}, \mathbf{b}, \mathbf{t}, \mathbf{d}, \mathbf{f}, \mathbf{v}, \mathbf{m}, \mathbf{n} />>/ \mathbf{k}, \mathbf{g}, \mathbf{n} />>/ \mathbf{s}, \mathbf{z} />>/ \mathbf{l}, \mathrm{R} />>/ \mathbf{N} />>/ \mathbf{f}, \mathbf{3}, \mathbf{r} /$ \\ Fonte: Matzenauer e Costa (2017)}

De acordo com a Teoria Autossegmental (CLEMENTS; HUME, 1995), consoantes complexas são aquelas caracterizadas por apresentarem, no mínimo, duas articulações diferentes, uma articulação primária no ponto de consoante e uma secundária no nó vocálico. Conforme a Figura 2, é possível observar a estrutura da consoante complexa $/ K /$. 
Figura 2. Estrutura da consoante complexa / $K /$

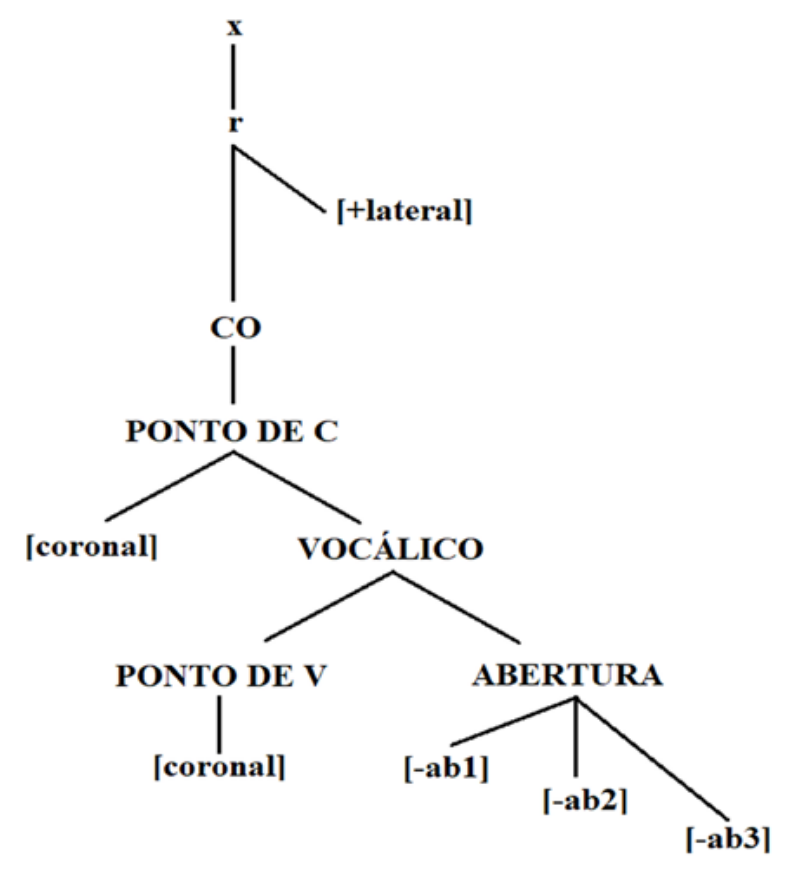

Fonte: Miranda e Matzenauer (2010)

Quanto às estratégias utilizadas pelas crianças durante a aquisição das soantes palatais, Matzenauer (2000) verificou para a líquida palatal seis processos principais: produção; apagamento; produção da líquida lateral alveolar, realização de [j], produção [lj] e realização de [li]. Teixeira e Miranda (2010), ao estudarem as escritas de crianças dos anos iniciais, observaram que os estudantes lançam mão de estratégias que se assemelham àquelas observadas por Matzenauer (2000) em estudo sobre aquisição fonológica.

Tendo em vista que a criança, durante o processo de aquisição da escrita, estabelece conexões entre o conhecimento fonológico e o alfabético, é possível pensar que durante esse processo ela cria hipóteses para grafar os segmentos da língua a partir de conhecimentos já existentes em seu sistema linguístico. A respeito do processo de aquisição da escrita, Ferreiro e Teberosky (1999), com base na perspectiva construtivista de Piaget e na teoria gerativista de Chomsky, constataram que, antes mesmo de efetivamente entrar em contato com a escrita na escola, a criança traz consigo informações e hipóteses acerca do sistema notacional em aquisição.

Vale ressaltar que este estudo baseia-se na perspectiva de erro adotada pelo GEALE, que interpreta as formas gráficas produzidas pelas crianças, após a conquista da base alfabética, como formas provisórias de saber, conforme Freire (1995). O erro 
- | A líquida palatal do português na diacronia e na aquisição da escrita

analisado como construtivo pode auxiliar aqueles que estudam aquisição da linguagem a investigar o saber construído pelas crianças a partir de suas experiências linguísticas.

Considerando as estratégias reportadas em estudos sobre a aquisição das soantes palatais e as motivações fonológicas que envolvem essas estratégias, evidencia-se a complexidade de tais consoantes, que oferecem dificuldades à criança no processo inicial de aquisição. Essa complexidade é expressa adequadamente pela Teoria Autossegmental, especificamente a Geometria de traços, conforme proposta por Clements e Hume (1995) e exemplificada na Figura 2.

\section{Procedimentos metodológicos}

Para tratar da líquida palatal do português, neste estudo, foram analisados dados relativos à aquisição da escrita do português e levantadas, em bibliografias que tratam da evolução do latim ao português, considerações sobre os processos envolvidos na evolução da consoante palatal $/ K /$. O corpus deste trabalho é constituído por grafias da líquida palatal de crianças brasileiras e portuguesas e de apontamentos de autores sobre os metaplasmos. Os dados que tratam da escrita foram extraídos do terceiro e quarto estratos do Banco de Textos sobre Aquisição da Linguagem Escrita (BATALE) e, de cada estrato, foram selecionados, respectivamente, textos classificados como alfabéticos ${ }^{7}$ de crianças brasileiras de $1^{\mathrm{a}}$ a $3^{\mathrm{a}}$ série e crianças portuguesas de $1^{\mathrm{o}}$ a $3^{\circ}$ ano.

Após a seleção dos textos, foram extraídas todas as grafias nas quais havia contexto para a soante líquida palatal. Os dados foram organizados em dois grupos: erros e acertos. Em seguida, procedeu-se à análise dos erros tomando como base as categorias utilizadas por Teixeira e Miranda (2010), a saber, erros relacionados a falhas do conhecimento relativo à representação ortográfica das soantes (uso apenas do " $\mathrm{h}$ " ou do "nh" pelo "lh", por exemplo); e erros que evidenciam aspectos fonológicos (uso do "li" ou do "I" para a líquida palatal).

Para a comparação entre os dados de escrita, foram levantados os processos encontrados na evolução diacrônica do latim ao português a partir de gramáticas históricas. A bibliografia usada para obter os processos envolvidos na evolução da líquida palatal foi extraída de livros que tratam da evolução histórica do latim ao português, conforme citados a seguir:

7 São considerados alfabéticos aqueles textos que obedecem ao critério da legibilidade. 
i. Crestomatia arcaica - Nunes (1967);

ii. Compêndio de gramática histórica do português - Nunes (1975);

iii. Do latim ao português: fonologia e morfologia histórica da língua portuguesa - Williams (2001);

iv. História da Língua Portuguesa - Spina (2008);

v. História da Língua Portuguesa - Silva Neto (1970);

vi. História da língua portuguesa - Teyssier (2004);

vii. O português arcaico: fonologia - Silva (2001);

viii. Pontos de gramática histórica - Coutinho (1976).

Da literatura analisada, foram extraídas as palavras que envolviam a evolução da líquida palatal e as considerações dos autores sobre os processos envolvidos na formação das soantes palatais no português.

\section{Análise e discussão dos dados}

Conforme mencionado anteriormente, o corpus deste estudo é composto por dados de aquisição da escrita da líquida palatal. Nesta seção, serão discutidos os dados que tratam da aquisição da escrita, com base na proposta de Teixeira e Miranda (2010), e os processos envolvidos na diacronia da consoante complexa.

\section{A líquida palatal na escrita de crianças brasileiras}

Os dados de crianças brasileiras são compostos por 67 grafias da líquida palatal retiradas de 287 textos que fazem parte do terceiro Estrato do BATALE, o qual é composto por produções de crianças do ensino fundamental de escolas públicas da cidade de Pelotas (RS - Brasil) coletadas em 2009. Na computação realizada com as 67 grafias a serem estudadas, verificou-se um percentual de $73 \%$ de acertos, que corresponde a 49 grafias corretas de l $h$ e $27 \%$ de erros, equivalente a 18 erros na grafia desse segmento. Os erros foram classificados de acordo com Teixeira e Miranda (2010), por série e tipos de erros encontrados em cada série, conforme Tabela 1: 
- | A líquida palatal do português na diacronia e na aquisição da escrita

Tabela 1. Percentual de erros por série

\begin{tabular}{c|c|c|c}
\hline & $\mathbf{1}^{\mathbf{a}}$ série & $\mathbf{2}^{\mathbf{a}}$ série & $\mathbf{3}^{\mathbf{a}}$ série \\
\hline Contextos & 02 & 30 & 35 \\
\hline Erros & 0 & 0 & 18 \\
\hline Percentual & 0 & 0 & $51,4 \%$ \\
\hline
\end{tabular}

Fonte: Elaboração própria

Como pode ser observado na Tabela 1 , as ocorrências de $/ K /$ encontradas nas $1^{\text {a }}$ e $2^{\mathrm{a}}$ séries são de acertos, já os dados da $3^{\mathrm{a}}$ série apontam $51,4 \%$ de erros de grafia da líquida palatal, sendo próximo o número de ocorrências de grafias corretas e incorretas das crianças da $3^{\text {a }}$ série.

A análise em percentuais de erros, conforme mostra a Figura 3, aponta que nos dados das três séries compostas por crianças brasileiras ocorreu o predomínio da grafia de $i$ para $l h$, com $89 \%$ e um número bem inferior da grafia de li para $l h$, correspondendo a 11\% dos erros encontrados na grafia da líquida palatal das crianças brasileiras estudadas.

Figura 3. Tipos e percentuais de erros do terceiro Estrato

\section{Distribuição dos erros conforme o tipo}

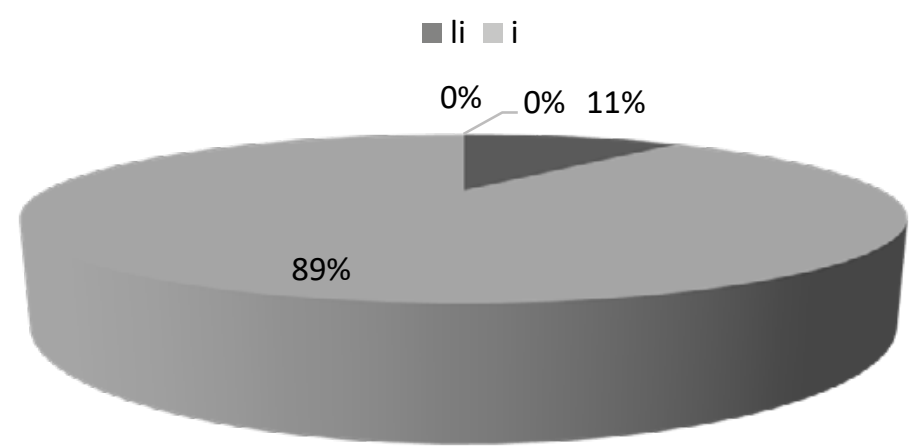

Fonte: Elaboração própria

Embora o número de dados seja pequeno, estudos de outros estratos do BATALE, como o de Teixeira e Miranda (2010), ao analisarem as soantes palatais do português, observam que as crianças apresentam dificuldades para a grafia da líquida palatal. Corrobora-se, assim, os achados deste e de outros estudos, que apontam para a complexidade da consoante. 


\section{Aquisição da escrita de crianças portuguesas - Quarto estrato}

Os dados que tratam da grafia da líquida palatal por crianças portuguesas foram extraídos do quarto estrato do BATALE que é composto por textos coletados em escolas públicas da cidade do Porto (Portugal) no ano de 2009. Entre as duas amostras, Brasil e Portugal, há uma diferença significativa no conjunto de textos que compõem cada estrato, 287 e 712 , respectivamente.

Dos 712 textos analisados do quarto Estrato, foram extraídas grafias com erros e com acertos da líquida palatal, totalizando 4.737 grafias. Nesses dados, o número de acertos prevaleceu, com 93,6\%, e os erros de grafia de $l$ corresponderam a $6,4 \%$.

Os erros equivalem a 304 grafias da líquida palatal e foram divididos por ano escolar e tipo de erro, seguindo a proposta de Teixeira e Miranda (2010). Os percentuais de erros expostos na Tabela 2 foram obtidos a partir do cálculo separado de cada ano escolar e demonstram que as crianças da $1^{\mathrm{a}}$ série foram as que apresentaram maior dificuldade de grafia da líquida palatal.

Tabela 2. Percentual de erros em cada ano escolar

\begin{tabular}{c|c|c|c}
\hline & $\mathbf{1}^{\mathbf{0}}$ ano & $\mathbf{2}^{\mathbf{o}}$ ano & $\mathbf{3}^{\mathbf{0}}$ ano \\
\hline Contextos & 135 & 2.025 & 2.577 \\
\hline Erros & 19 & 170 & 115 \\
\hline Percentual & $14,07 \%$ & $8,39 \%$ & $4,46 \%$ \\
\hline
\end{tabular}

Fonte: Elaboração própria

Na etapa seguinte do estudo, os 304 erros de grafias encontrados nos três anos escolares foram classificados e computados percentualmente considerando onze tipos de erros, conforme mostra a Figura 4. 
Figura 4. Tipos e percentuais de erros do terceiro estrato



Fonte: Elaboração própria

Dada a variedade de tipos encontrada na amostra das crianças portuguesas, é importante salientar a presença de erros relacionados a aspectos da ortografia, quais sejam, o uso de " $\mathrm{h}$ ", "nh" e "ch" para "lh", os quais totalizam 63\% dos dados. Resultados que chamam atenção também para dificuldades que envolvem as grafias de dígrafos com " $h$ " e que vêm sendo observados em estudos desenvolvidos a partir da análise de outros estratos do BATALE.

\section{Erros fonológicos das crianças brasileiras e portuguesas}

A partir dos erros obtidos nos dois estratos, conforme apresentado anteriormente, foram selecionados os erros de grafia da líquida palatal decorrentes de motivação fonológica. Sobre a grafia do $l h$, os dados apontam que as crianças brasileiras e portuguesas apresentam dificuldades na grafia da líquida palatal decorrentes de alguma motivação fonológica, conforme exemplos do Quadro 2. 
Quadro 2. Erros do terceiro e quarto estratos

\begin{tabular}{|l|l|}
\hline Estrato 3 - Crianças brasileiras & Estrato 4 - Crianças portuguesas \\
\hline $\mathrm{Ih} \rightarrow \mathrm{li}$ - armadilha $\rightarrow$ armadilia & $\mathrm{lh} \rightarrow \mathrm{I}$ - vermelho -vermelo \\
\hline $\mathrm{Ih} \rightarrow \mathrm{i}$ - velha $\rightarrow$ veia & $\mathrm{lh} \rightarrow \mathrm{r}$ - vermelho - vermero \\
\hline & $\mathrm{lh} \rightarrow \mathrm{i}$ - olhos - oios \\
\hline & apagamento - melhor - meor \\
\hline & $\mathrm{I} \rightarrow \mathrm{lh}$ - ela - elha \\
\hline
\end{tabular}

Fonte: Elaboração própria

De acordo com os dados apresentados no Quadro 2, as crianças brasileiras e portuguesas produziram seis tipos de erros considerados de motivação fonológica para a líquida palatal. Desses erros apenas a grafia de $i$ para $/ h$ foi encontrada nos dados dos dois estratos. Quanto aos anos escolares, as crianças brasileiras apresentaram erros de grafia de $l h$ apenas na terceira série, já as crianças portuguesas apresentaram erros de grafia da líquida palatal nos três anos escolares. Além disso, observou-se que as crianças do terceiro estrato apresentaram apenas dois erros, enquanto as do quarto estrato produziram seis tipos de erros. Os erros listados no Quadro 2 podem ser interpretados da seguinte forma:

- A grafia de li para lh, por exemplo, como em armadilia para a palavra armadilha, conforme mencionado anteriormente, ocorreu apenas em dados de crianças brasileiras. Além disso, também é um tipo de estratégia encontrada em dados de aquisição fonológica da consoante complexa. Esse mesmo erro já foi observado em estudos de Teixeira e Miranda (2008) ao analisarem dados de escrita espontânea de crianças brasileiras de $1^{\mathrm{a}}$ a $4^{\mathrm{a}}$ série do ensino fundamental;

- De acordo com a proposta de Calabrese (1988), quando um sistema fonológico tem seu grau de complexidade excedido, são utilizadas estratégias de simplificação, tais como: Fissão, Desligamento e Negação. A Fissão é uma operação que divide um conjunto de traços que contém uma configuração não permitida em dois conjuntos sucessivos; o Desligamento é a operação na qual um dos traços complexos da configuração não permitida é desligado; e a Negação é a operação que muda os valores dos traços incompatíveis da configuração não permitida por valores opostos;

- Em conformidade com a proposta de Calabrese (1988), a passagem de lh para li é interpretada como processo de fissão, que transforma uma unidade de tempo $\mathrm{X}$ em duas unidades XX por causa do excesso de complexidade para o sistema fonológico. 
Figura 5. Representação da sequência [li] a partir de uma consoante complexa



Fonte: Miranda (2014, p. 65)

- As grafias de $i$ para o lh, observadas na palavra veia para velha em dados de crianças brasileiras e na escrita de oios para olhos em textos de crianças portuguesas, são dados que evidenciam outro tipo de erro produzido pelas crianças para escrita da consoante palatal $/ \Lambda /$. Essa estratégia foi encontrada nas turmas de $3^{\mathrm{a}}$ série do terceiro estrato e nas turmas de $1^{\circ}$ e $3^{\circ}$ anos do quarto estrato. De acordo com a proposta da Teoria Autossegmental, esse processo mostra o efeito de desligamento da constrição primária consonantal da consoante complexa;

- A grafia de l para lh, como em vermelo para vermelho, foi detectada apenas nos dados de crianças portuguesas, já em dados de aquisição da linguagem, Matzenauer (2000) observou a troca em dados de crianças brasileiras. $\mathrm{Na}$ aquisição da escrita, Miranda (2014), em estudos desenvolvidos no GEALE, detectou esse mesmo tipo de erro em textos de crianças brasileiras. Esse processo ocorre devido ao desligamento da constrição secundária vocálica do segmento da consoante complexa. Dessa forma, a estrutura apresenta apenas a constrição primária consonantal;

- A grafia do $r$ para o lh, por exemplo, em vemero para vermelho, é um tipo de erro constatado somente nos dados de escrita das crianças portuguesas. Essa estratégia é semelhante àquelas observadas em dados de aquisição da fala, ainda que em dados episódicos, as crianças fazem essa troca durante a 
aquisição do sistema fonológico. Estudos de Miranda (2014), em aquisição da escrita, observaram a troca do $r$ - fraco pela líquida palatal e, para a autora, a troca é justificada pelo fato das duas consoantes serem as últimas líquidas adquiridas no processo de desenvolvimento fonológico. Além disso, essas produções de $r$-fraco para a consoante $/ K /$ corroboram a argumentação de Matzenauer-Hernadorena (1996) de que a rótica alveolar tem, assim como as soantes palatais, uma constituição interna complexa. No estudo, a autora defende que todas as líquidas são complexas;

- O apagamento da líquida palatal foi encontrado nos textos pertencentes ao quarto estrato e foram verificados três tipos de erros e em dois anos escolares, como em: mior para melhor, meores para melhores e meor para melhor. Os apagamentos verificados da líquida palatal corroboram a ideia de que as soantes palatais são problemáticas na escrita inicial, assim como na aquisição fonológica, devido à sua complexidade interna, que é resultante de duas constrições, uma primária e outra secundária. Em Miranda (2013), tem-se uma hipótese explicativa para apagamentos da soante relacionada à neutralização das vogais pretônicas, pois de acordo com a autora a neutralização da pretônica ( $\mathrm{m}[\mathrm{e}]$ lhor $\sim \mathrm{m}[\mathrm{i}]$ lhor) pode influenciar no não registro da soante líquida palatal por efeito do Princípio do contorno obrigatório (OCP) ${ }^{8}$;

- A troca no registro de uma consoante simples $/ \mathrm{I} /$ pela complexa $/ K /$, como em elha para ela, pode ser interpretado como um erro de influência ortográfica, ao pensar-se que a criança está em um processo de aprendizagem do dígrafo que corresponde à líquida palatal e, portanto, pode utilizá-lo de forma indiscriminada.

\section{Comparação entre dados de escrita e da diacronia da líquida palatal}

Os processos com influência fonológica encontrados nos dados de aquisição da escrita da líquida palatal, citados e discutidos anteriormente, estão expostos no Quadro 3, juntamente aos metaplasmos observados na evolução do latim ao português dessa mesma consoante complexa.

8 OCP (Obligatory Contour Principle): Princípio do Contorno Obrigatório é um princípio básico da Teoria Autossegmental, em que se proíbe elementos, traços ou nós adjacentes idênticos em uma dada camada, bem como regras que possam violar tal princípio. 
- | A líquida palatal do português na diacronia e na aquisição da escrita

Quadro 3. Processos envolvendo a aquisição da escrita e a diacronia da líquida palatal

\begin{tabular}{|l|l|l|l|}
\hline \multicolumn{2}{|l|}{ Aquisição } & \multicolumn{2}{l|}{ Diacronia } \\
\hline $\mathrm{lh} \rightarrow \mathrm{li}$ & armadilha $\rightarrow$ armadilia & $\mathrm{cl} \rightarrow \mathrm{lh}$ & oc(u)lu> olho \\
\hline $\mathrm{lh} \rightarrow \mathrm{i}$ & velha $\rightarrow$ veia & $\mathrm{pl} \rightarrow \mathrm{lh}$ & $\mathrm{scop}(\mathrm{u}) \mathrm{lu}>$ scoclu $>$ escolho \\
\hline $\mathrm{lh} \rightarrow \mathrm{I}$ & vermelho $\rightarrow$ vermelo & $\mathrm{bl} \rightarrow \mathrm{lh}$ & trib(u)lu>trilho \\
\hline $\mathrm{lh} \rightarrow \mathrm{r}$ & vermelho $\rightarrow$ vermero & $\mathrm{gl} \rightarrow \mathrm{lh}$ & teg(u)la $>$ telha \\
\hline apagamento & melhor $\rightarrow$ meor & $\mathrm{tl} \rightarrow \mathrm{lh}$ & vetlu>velho \\
\hline $\mathrm{I} \rightarrow \mathrm{lh}$ & ela $\rightarrow$ elha & $\mathrm{ll} \rightarrow \mathrm{lh}$ & alliu $>$ alho \\
\hline & & $\mathrm{li} \rightarrow \mathrm{lh}$ & filiu $>$ filho \\
\hline & & $\mathrm{Il} \rightarrow \mathrm{lh}$ & caballariu $>$ cavalheiro \\
\hline
\end{tabular}

Fonte: Elaboração própria

Em relação aos metaplasmos mencionados, é interessante atentar para alguns apontamentos feitos por autores consultados durante o levantamento dos dados da diacronia das líquidas palatais. Na perspectiva de Teyssier (2004), quando ocorre o apagamento da vogal / $\mathrm{u} /$, no caso de oculum> oclu, o $c$ antes pronunciado como $/ \mathrm{k}$ / passa iode $/ \mathrm{j} /$, formando uma nova sequência /jl/, que em galego-português passa para líquida palatal. Para Neuschrank (2011), nas sequências /gl/, /pl/, /bl/ e /tl/ ocorre o mesmo processo observado na sequência $/ \mathrm{kl} /$.

O segmento /lli/ também deu origem à líquida palatal, como em alliu>alho. Nesse metaplasmo, primeiramente, ocorre o apagamento de uma das consoantes simples / $/$, pois essas duas consoantes juntas violam OCP, que proíbe a adjacência de segmentos idênticos. Após o apagamento, ocorre a palatalização da consoante alveolar e, para isso, realiza-se o espraiamento do nó vocálico do segmento seguinte para o ponto de consoante da lateral alveolar /l/. Com isso, transformando o segmento simples / / em um segmento complexo, contendo duas articulações, uma primária consonantal e outra secundária vocálica.

Da evolução de /li/ ou /I/ também decorre a líquida palatal, como em: alienu>alheio e palea>palha. Nesse processo, ocorre a palatalização da consoante $/ \mathrm{I}$. Como na mudança de $/$ lli/ para $/ K /$, o que motiva a palatalização é a presença da semivogal $/ \mathrm{j} /$ e da vogal /e/ que sucedem a lateral alveolar. A formação da consoante complexa $/ \kappa /$ se dá com o espraiamento do nó vocálico do segmento posterior para $\mathrm{O}$ ponto de consoante de $/ \mathrm{I} /$.

Ao comparar os processos utilizados pelas crianças ao grafarem a líquida palatal com os processos da diacronia dessa mesma consoante, é possível observar que: 
- na grafia de li para $l h$, produzida durante a aquisição da escrita, tem-se uma grafia que corresponde ao que na fonologia é tratado como uma Fissão de nós. De acordo com Calabrese (1988), essa simplificação da consoante complexa consiste na divisão de um conjunto de traços em dois conjuntos sucessivos, cada um contendo características diferentes do segmento inicial. A criança, ao grafar uma consoante simples e a vogal /i/ no lugar da líquida palatal, estaria simplificando o segmento complexo por meio da estratégia da Fissão;

- na diacronia ocorre o espraiamento do nó vocálico da semivogal /i/ para a consoante $/ \mathbb{I} /$, processo inverso ao observado na aquisição da escrita. Esse processo de espraiamento é observado na evolução de todos os segmentos que originam a líquida palatal. O que difere entre os processos de formação dessa consoante complexa são as etapas que precedem a constituição das sequências /li/ ou /jl/, em que há o espraiamento do nó vocálico da semivogal para o / / e, consequentemente, a forma da consoante complexa.

Os demais processos verificados na escrita também resultam, via de regra, em grafias que correspondem a formas menos complexas no que se refere à constituição interna da soante. Ao mesmo tempo, são dados que revelam a estrutura interna, ou pelo menos, parte dela, trazendo reforço à ideia de que internamente tais consoantes são constituídas por dois articuladores, um consonantal e outro vocálico.

\section{Considerações finais}

Considerando a complexidade da líquida palatal na aquisição da linguagem (MATZENAUER, 2000) e na aquisição da escrita (TEIXEIRA; MIRANDA, 2008, MIRANDA, 2014), bem como o fato de essa soante não integrar o sistema consonantal do latim clássico, este estudo buscou comparar os processos ocorridos na diacronia e na aquisição da consoante complexa, dando ênfase às escritas produzidas pelas crianças logo após a compreensão dos princípios do sistema de escrita alfabética, especificamente aquele princípio que diz respeito à relação entre as unidades básicas do alfabeto e as unidades de segunda articulação da língua.

Ao realizar a comparação dos erros verificados nos dois estratos analisados com os metaplasmos apontados pelas bibliografias consultadas, foi possível verificar que os processos ocorrem em sentido contrário - na diacronia e na aquisição da escrita. Na diacronia, o processo de espraiamento do nó vocálico da semivogal /i/ para a consonante /l/ transforma segmentos simples em complexos e, na aquisição, segmentos complexos são produzidos como simples. Assim, os processos da diacronia e da aquisição da escrita 
- | A líquida palatal do português na diacronia e na aquisição da escrita

podem ser compreendidos como inversos, visto que ocorre uma complexificação dos segmentos na evolução da líquida palatal e uma simplificação no processo de aquisição da escrita dessa consoante. Os resultados obtidos na análise e comparação dos dados deste estudo, embora não possam ser generalizados, corroboram a ideia de complexidade referente à líquida palatal em consonância com os estudos fonológicos (MATZENAUERHERNANDORENA, 1994 e 2000; WETZELS, 1997).

Por fim, salienta-se que este estudo ressalta a importância das grafias iniciais, pois, a partir delas, pode-se ter indícios para análises fonológicas e para a reflexão sobre os aspectos relacionados aos processos evolutivos da língua, já que ambos mostram o efeito do tempo sobre as mudanças fônicas nos sistemas linguísticos, seja no que se refere ao desenvolvimento da linguagem seja no que diz respeito à história da língua.

\section{REFERÊNCIAS}

CALABRESE, A. Towards a theory of phonological alphabets. Cambridge: Massachusetts, 1988. Doctoral dissertation - MIT.

CAMARA JR, J. M. História e estrutura da língua portuguesa. Rio de Janeiro: Padrão livraria e editora, 1975.

CLEMENTS, G.; HUME, E. V. The internal organization of speech sounds. In:

GOLDSMITH. J. (org.). The Handbook of Phonological Theory. London: Black-well, 1995.

COUTINHO, I. L. Pontos de gramática histórica. 7. ed. rev. Rio de Janeiro: Ao livro técnico, 1976.

FERREIRO, E.; TEBEROSKY, A. Psicogênese da Língua Escrita. Tradução Diana Myriam Lichtenstein, Liana Di Marco e Mário Corso. Porto Alegre: Artmed, 1999.

FREIRE, P. À sombra desta mangueira. São Paulo: Editora Olho D’Água, 1995.

MATZENAUER-HERNANDORENA, C. L. A Geometria de Traços na Representação das Palatais na Aquisição do Português. Letras de Hoje, Porto Alegre, v. 29, n. 4, p. 1-167, dez. 1994. 
MATZENAUER-HERNANDORENA, C. L. Relações implicacionais na aquisição da fonologia. Letras de Hoje, v. 31, n. 2, p. 67-76, 1996.

MATZENAUER-HERNANDORENA, C. L. As soantes palatais no português brasileiro: uma discussão sobre seu status fonológico. In: GARTNER, E. et al. (ed.). Estudos de gramática portuguesa (II). v. 13. Frankfurt am Main: TFM, 2000. p. 301-321.

MATZENAUER-HERNANDORENA, C. L. Homogeneidade/heterogeneidade na aquisição e na variação fonológica. In: VANDRESEN, P. (org.). Variação e mudança no português falado na região sul. Pelotas: EDUCAT, 2002. p. 95-114.

MATZENAUER, C. L.; COSTA, T. Aquisição da fonologia em língua materna: os segmentos. In: FREITAS, M. J.; SANTOS, A. L. (ed.). Aquisição da língua materna e não materna: questões gerais e dados do português. Berlin: Language Science Press, 2017. p. 51-70.

MEZZOMO, C. L.; RIBAS, L. P. Sobre a aquisição das Líquidas. In: LAMPRECHT, R. R. et al. Aquisição Fonológica do Português - Perfil de desenvolvimento e subsídios para terapia. Porto Alegre: Artmed Editora S.A., 2004. p. 95-109.

MIRANDA, A. R. M. Informação fonológica na aquisição da escrita. Revista estudos linguísticos contemporâneos: diferentes olhares, Editora Cultura Acadêmica, v. 23, p. 11-35, 2013.

MIRANDA, A. R. M. A fonologia em dados de escrita inicial de crianças brasileiras. Revista Linguística, Montevideo, v. 30, p. 45-80, dez. 2014.

MIRANDA, A. R. M.; MATZENAUER, C. L. B. Aquisição da fala e da escrita: relações com a Fonologia. In: MIRANDA. A. R. M.; CUNHA, A. P. N. (org.). A aquisição e o ensino da linguagem escrita - Cadernos da Educação, Ed. UFPel - Pelotas, ano 19, n. 35, p. 359405, jan.-abr. 2010.

NEUSCHRANK, A. Do Latim ao Português: um continuum à luz da teoria fonológica. 2011. Dissertação (Mestrado em Linguística Aplicada) - Universidade Católica de Pelotas, Pelotas, 2011.

NUNES, J. J. N. Crestomatia arcaica. 6. ed. Lisboa: Editora Livraria Clássica, 1967. 
- | A líquida palatal do português na diacronia e na aquisição da escrita

NUNES, J. J. N. Compêndio de gramática histórica portuguesa - fonética e morfologia.

8. ed. Lisboa: Editora Livraria Clássica, 1975.

SILVA NETO, S. Fontes do latim vulgar. 3. ed. Rio de Janeiro: Livraria Acadêmica, 1956.

SILVA NETO, S. História da Língua Portuguesa. 2. ed. Rio de Janeiro: Livros de Portugal, 1970.

SILVA, R. V. M. e. O português arcaico: fonologia. 4. ed. São Paulo: Contexto, 2001.

SPINA, S. (org.). História da Língua Portuguesa. Cotia: Ateliê Editorial, 2008.

TAVARES, F. C. As soantes palatais do português na diacronia e na aquisição

da linguagem escrita. 2019. Dissertação (Mestrado em Estudos da Linguagem) Universidade Federal de Pelotas, Pelotas, 2019.

TEIXEIRA, S. de M.; MIRANDA, A. R. M. Descrição e análise dos erros ortográficos referentes à grafia das soantes palatais e discussão sobre seu status fonológico. In: $8^{\circ}$ Encontro CELSUL, 2008, Porto Alegre. Anais do $8^{\circ}$ Encontro do CELSUL. Pelotas: EDUCAT, 2008. v. 1. p. 1-9.

TEIXEIRA, S. de M.; MIRANDA, A. R. M. O que os estudos de 2008 a 2010 revelam acerca da grafia das soantes palatais? In: XIX Congresso de Iniciação Científica, XII Encontro de Pós-Graduação e I Mostra Científica, 2010, Pelotas. Anais do XIX Congresso de Iniciação Científica, XII Encontro de Pós-Graduação e I Mostra Científica. Pelotas: Editora Universitária/ UFPEL. p. 1-4.

TEYSSIER, P. História da língua portuguesa. 2. ed. São Paulo: Martins Fontes, 2004.

WETZELS, W. Leo. The lexical representation of nasality in Brazilian Portuguese. Probus, v. 9, p. 203-232, 1997.

WILLIAMS, E. B. Do latim ao português: fonologia e morfologia histórica da língua portuguesa. 7. ed. Rio de Janeiro: Tempos Brasileiros, 2001. 
COMO CITAR ESTE ARTIGO: TAVARES, Franciele Collovini; MIRANDA, Ana Ruth Moresco. A líquida palatal do português na diacronia e na aquisição da escrita. Revista do GEL, v. 17, n. 1, p. 308-328, 2020. Disponível em: https://revistas.gel.org.br/rg

DOI: http://dx.doi.org/10.21165/gel.v17i1.2770

Submetido em: 13/10/2019 | Aceito em: 23/05/2020. 